\title{
Goitre in Ethiopia
}

\author{
BY ZEWDIE WOLDE-GEBRIEL AND TESHOME DEMEKE* \\ Ethiopian Nutrition Institute, PO Box 5654, Addis Ababa, Ethiopia \\ AND CLIVE E. WEST † AND FRITS VAN DER HAAR \\ Department of Human Nutrition, Wageningen Agricultural University, PO Box 8129, $6700 \mathrm{EV}$ \\ Wageningen, The Netherlands
}

(Received 5 August 1991 - Accepted 21 January 1992)

\begin{abstract}
A stratified goitre survey was conducted on 35635 schoolchildren and 19158 household members in all Regions of Ethiopia except Eritrea and Tigrai. The gross goitre prevalence (mean of male and female values) among schoolchildren and household members was 30.6 and 18.7\% respectively, while that of visible goitre was 1.6 and $3.2 \%$ respectively. Prevalence was higher in females (27.3\% in household members and $36.1 \%$ in schoolchildren) than in males $(10.1 \%$ in household members and $25.1 \%$ in schoolchildren) and increased with age more in females than in males. The prevalence rates at higher altitudes were higher than those at lower altitudes in both schoolchildren and household members. Using an epidemiological model the consequences of iodine deficiency, including cretinism and maternal wastage, have been estimated.
\end{abstract}

Goitre: Iodine: Cretinism

Iodine deficiency disorders (IDD) encompass a variety of conditions including goitre, mental disorders and milder psychomotor defects, abortions, stillbirths, and increased perinatal and infant mortality. Goitre was known to the Hindus as early as $2000 \mathrm{BC}$, to the Egyptians by $1500 \mathrm{BC}$, and in Western Europe in the 1st century AD (Langer, 1960). In Ethiopia there is a lack of historical documentation on the occurrence of goitre, as is the case for many other diseases. Nevertheless, early travellers in the country and physicians during the Italian invasion of Ethiopia in the Second World War reported cases of goitre in various parts of the country (Kelly \& Snedden, 1960). More recent studies demonstrated that goitre is one of the nutrition diseases of public health significance in certain areas of the country (Interdepartmental Committee on Nutrition for National Defence, 1959; Demonstration and Evaluation Team, 1965; Popov, 1967; Hofvander, 1970; Miller et al. 1976). The primary objective of the present study was to estimate the prevalence of goitre throughout the country. A second objective was to estimate the prevalence of other manifestations of IDD based on epidemiological models relating the prevalence of these manifestations to that of goitre.

\section{MATERIAL AND METHODS}

\section{Sampling}

The study was conducted in the period between March 1980 and July 1981. Data on the population of urban and semi-urban areas, altitude, and agroecological zones were obtained from the Central Statistical Authority, Mapping Authority, and Ministry of

* Present address: Ministry of Health, PO Box 1234, Addis Ababa, Ethiopia.

$\dagger$ For reprints. 
Agriculture respectively. All Administrative Regions of the country were studied except Eritrea and Tigrai which were excluded for security reasons. First-stage stratification was based on the population of the urban and semi-urban areas while subsequent stratification was based on Administrative Region and altitude, since $89 \%$ of the population of the country live in areas more than $1400 \mathrm{~m}$ above sea level (Kloos et al. 1988). Schoolchildren and household members were studied.

In towns where there was more than one government primary school, one was selected in consultation with the educational authorities in order to ensure that those selected for the survey of schoolchildren were representative of all sectors in the area. All children present on the day of examination were included. Through such a procedure, a total of 35635 schoolchildren (19159 boys and 16476 girls) were enrolled in the study.

In the household survey, a total of 19158 subjects (7649 males and 11509 females) were examined in forty-two urban and semi-urban settings. The study sites were in thirty-eight provinces with a population of over 19 million out of the total of eighty-five provinces in the country which has a population of 50 million (Office of the Population and Housing Census Commission, 1984). All households in smaller semi-urban settings or in two 'kebeles' (urban dwellers' associations) in larger towns were registered by personnel employed for the purpose. From this list of households, 160 households were selected at random. All members of the selected households were requested to come to one central area, usually the kebele office or the local health institution for physical examination. The enumerators went to the houses when subjects did not report on time. Despite this effort, it was not easy to contact all adult males because of their preoccupation with their daily routine and reluctance to undergo health examination. A predesigned questionnaire was used to register members of households, their ages, sex, relationship to head of household, goitre grade and duration of stay in the area. On the same questionnaire, data on staple diet, frequency of consumption of kale (Brassica carinata), availability and type of latrine and source of drinking-water were also collected to determine whether there was any relationship between these variables and the occurrence of goitre. Consumption of goitrogens in foods including kale and faecal contamination of drinking water are putative goitrogenic factors (Gaitan, 1980).

\section{Physical examination}

The physical examination of all subjects was carried out by two of the authors (Z.W.-G., T.D.). Goitre classification was compared and standardized at the start of examinations at each new study site and at regular intervals throughout the survey. The thyroid gland was examined and graded according to techniques recommended by Perez et al. (1960) and modified by DeLange (1974) where grade 0 corresponds to no goitre, IA is palpable but not visible, IB is goitre easily visible with the neck extended, II is visible without extension of the neck, and III is large goitre visible from a distance. When the goitre grading was in doubt, the lower stage was always chosen. In the present study, gross goitre included stages IA, IB, II and III while visible goitre included stages II and III. Whenever nodular goitre was diagnosed, this was noted along with the goitre grade.

\section{Estimation of IDD rates}

Cretinism was estimated from an epidemiological model based on existing data from Asian countries, Zaire and Ecuador (Clugston et al. 1987; Hetzel et al. 1990). The symbols used have been modified for the sake of clarity:

$$
c_{g}=\exp \left(b_{0}+b_{i} g+b_{i i} g^{2}\right) /\left[1+\exp \left(b_{0}+b_{i} g+b_{i i} g^{2}\right)\right]
$$

where $c_{g}$ is prevalence (proportion) of cretinism estimated from the prevalence of gross goitre, $g$ is prevalence (proportion) of gross goitre, $b_{0}-9.3939, b_{i} 15.796$, and $b_{i i}-8.8026$. 
The rates (proportion of live births) of reproductive losses namely, neonatal death, stillbirth and miscarriage/infertility were estimated as follows:

$$
l_{n}=m_{n} c_{g}
$$

where $m_{n}$ is multiplier for $l_{n}, c_{g}$ is prevalence (proportion) of cretinism estimated from the prevalence of gross goitre, $l_{i}$ is rate of neonatal death $\left(m_{i} 0.602\right), l_{i i}$ is rate of stillbirths $\left(m_{i i} 0 \cdot 656\right)$, and $l_{i i i}$ is rate of miscarriage/infertility $\left(m_{i i i} 0.883\right)$.

Mild developmental handicaps, namely developmental delays, psychomotor defects and reduced mental performance, were estimated by multiplying prevalence of cretinism by three (Clugston et al. 1987; Hetzel et al. 1990). The calculations were carried out using the prevalence of goitre from the household survey since similar data were used in deriving the equations. The goitre rates for both sexes together were calculated by taking the mean of the rates for males and females. The 1990 population projection was based on the 1984 census of Ethiopia (Office of the Population and Housing Census Commission, 1984) while the crude birth rates were from the 1984 Regional census (Office of the Population and Housing Census Commission, 1989). The national crude birth rate used in the calculations was a weighted mean of the regional rates taking into account the number of household members examined in each region.

\section{Statistics}

Chi square test and multiple regression analysis were used for determining the significance of differences and correlations respectively.

\section{RESULTS}

\section{School survey}

The prevalence of goitre among schoolchildren at the different study sites by administrative regions of Ethiopia is shown in Table 1. The prevalence (mean of rates for boys and girls) of gross goitre among schoolchildren was $30.6 \%$ while that for visible goitre was $1.6 \%$ (Table 1). The prevalence of goitre was higher in schoolchildren living at higher altitudes than those at lower altitudes. The prevalence predictions have not been normalized for altitude. The slope $(s)$ and intercept $(i)$ of the linear regression of gross goitre $(\%)$ on altitude $(\mathrm{m})$ (means with their standard errors) are: $(n 41, r 0.37, s 0.0114$ (SE 0.0046), $i 6.03$ (SE 9.37)).

More girls were found to have goitre than boys (Tables 1 and 2). The difference between the sexes became more pronounced with age (Table 2). In boys the prevalence dropped from about $25 \%$ for those 18 years of age and younger to less than $10 \%$ for those 19 years of age and older. In girls, the prevalence continued to increase with age from $20 \%$ in girls $0-5$ years to more than $42 \%$ in those 19 years of age and over. The sex (male : female) ratio for gross goitre was $1: 1 \cdot 3$ for the age-group $6-12$ years, $1: 1.6$ for $13-18$ years, and $1: 5 \cdot 3$ for those above 19 years of age. From among those with visible goitre, twenty-one $(5 \cdot 7 \%)$ had nodular goitre.

\section{Household survey}

In the household survey an overall gross goitre prevalence of $10 \cdot 1 \%$ in males and $27-3 \%$ in females (mean of rates for males and females $18.7 \%$ ) was found (Table 3). Visible goitre prevalence was $0.34 \%$ in males and $5.9 \%$ in females (mean of males and females $3 \cdot 1 \%$ ). The rate of visible goitre was lower than $4 \%$ in males in all regions, while in females a rate as high as $32.9 \%$ was seen in Gondar town. Of those subjects with visible goitre, only thirty-one, $4.4 \%$, had nodular goitre which was seen at fifteen of the study sites. Assuming that the sample population is representative for the whole country, 2.5 million males and 6.8 million females would have goitre while 85000 males and 1.5 million females 


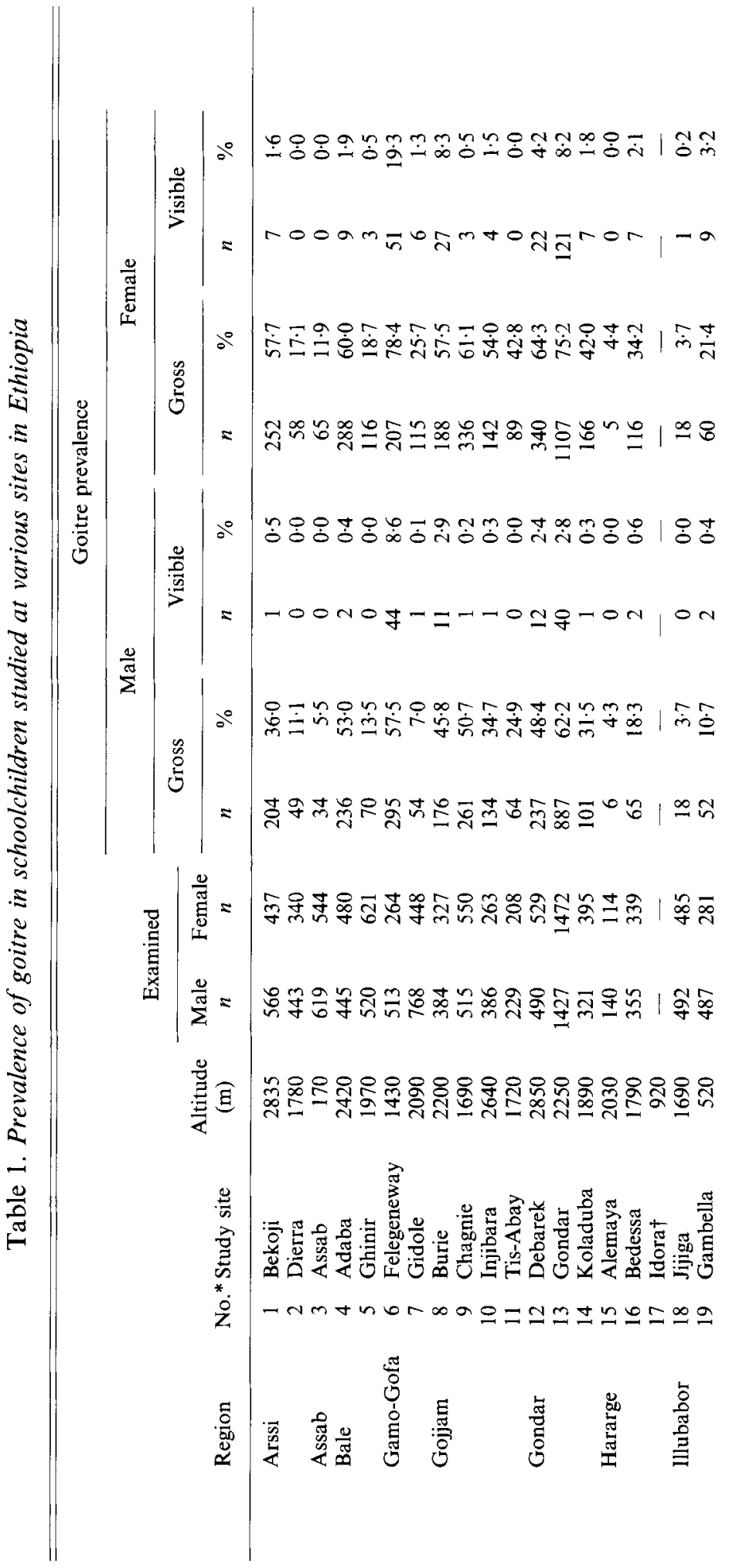




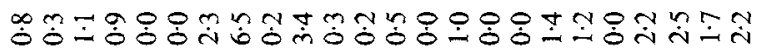

nmoroorn-aーー-

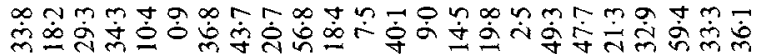

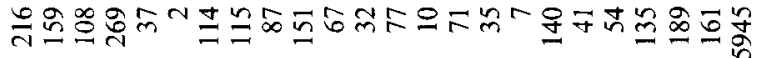

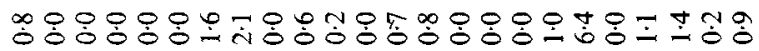

noogoonvon-omnooomgonm-I

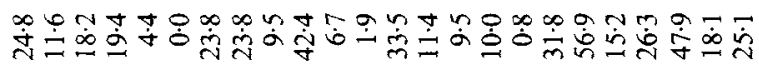

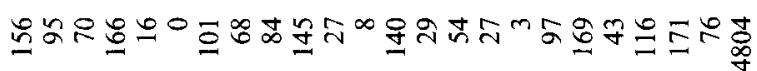

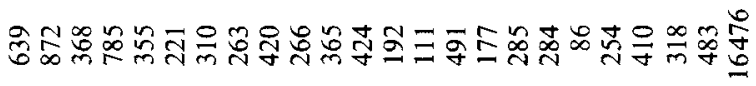

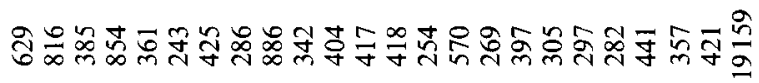

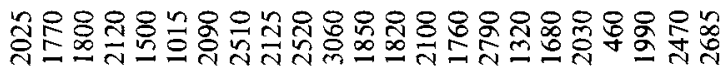

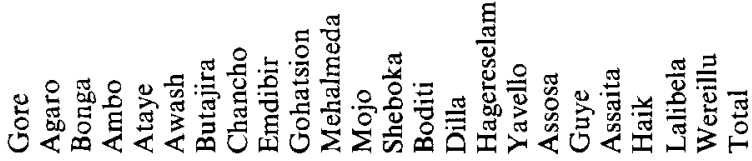

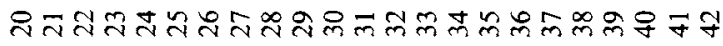

焉

$\stackrel{\circ}{\frac{\pi}{0}}$

$\begin{array}{ll}\frac{8}{3} & 0 \\ \overline{0} & 0\end{array}$ 
Table 2. Distribution of goitre grades by age and sex amongst schoolchildren at various sites in Ethiopia*

\begin{tabular}{|c|c|c|c|c|c|c|c|c|c|c|c|c|c|}
\hline \multirow{3}{*}{$\begin{array}{c}\text { Age } \\
\text { (years) }\end{array}$} & \multirow{3}{*}{$\begin{array}{c}\text { No. } \\
\text { examined }\end{array}$} & \multicolumn{10}{|c|}{ Goitre grade $\dagger$} & & \\
\hline & & \multicolumn{2}{|c|}{0} & \multicolumn{2}{|c|}{ IA } & \multicolumn{2}{|c|}{ IB } & \multicolumn{2}{|c|}{ II } & \multicolumn{2}{|c|}{ III } & \multicolumn{2}{|c|}{ Total goitre } \\
\hline & & $n$ & $\%$ & $n$ & $\%$ & $n$ & $\%$ & $n$ & $\%$ & $n$ & $\%$ & $n$ & $\%$ \\
\hline \multicolumn{14}{|l|}{ Male } \\
\hline $0-5$ & 19 & 14 & $73 \cdot 7$ & 5 & $26 \cdot 3$ & 0 & 00 & 0 & $0 \cdot 0$ & 0 & 0.0 & 5 & $26 \cdot 3$ \\
\hline $6-12$ & 13406 & 10002 & $74 \cdot 6$ & 2495 & $18 \cdot 6$ & 832 & $6 \cdot 2$ & 77 & 0.6 & 0 & $0 \cdot 0$ & 3404 & $25 \cdot 4$ \\
\hline $13-18$ & 5390 & 4023 & $74 \cdot 6$ & 901 & $16 \cdot 7$ & 369 & $6 \cdot 8$ & 92 & 1.7 & 5 & $0 \cdot 1$ & 1367 & $25 \cdot 4$ \\
\hline $19+$ & 344 & 316 & 91.9 & 20 & $5 \cdot 8$ & 5 & 1.5 & 3 & 0.9 & 0 & $0 \cdot 0$ & 28 & $8 \cdot 1$ \\
\hline Sub-total & 19159 & 14355 & $74 \cdot 9$ & 3421 & $17 \cdot 9$ & 1206 & $6 \cdot 3$ & 172 & 0.9 & 5 & 0.0 & 4804 & $25 \cdot 1$ \\
\hline \multicolumn{14}{|l|}{ Female } \\
\hline $0-5$ & 30 & 24 & $80 \cdot 0$ & 3 & $10 \cdot 0$ & 3 & $10 \cdot 0$ & 0 & $0 \cdot 0$ & 0 & $0 \cdot 0$ & 6 & $20 \cdot 0$ \\
\hline $6-12$ & 11724 & 7732 & $66 \cdot 0$ & 2587 & $22 \cdot 0$ & 1252 & $10 \cdot 7$ & 149 & $1 \cdot 3$ & 4 & $0 \cdot 0$ & 3992 & $34 \cdot 0$ \\
\hline $13-18$ & 4534 & 2667 & $58 \cdot 8$ & 1003 & $22 \cdot 1$ & 669 & $14 \cdot 8$ & 186 & $4 \cdot 1$ & 9 & $0 \cdot 2$ & 1867 & $41 \cdot 2$ \\
\hline $19+$ & 188 & 108 & $57 \cdot 4$ & 32 & $17 \cdot 0$ & 28 & 14.9 & 18 & $9 \cdot 6$ & 2 & $1 \cdot 1$ & 80 & $42 \cdot 6$ \\
\hline Sub-total & 16476 & 10531 & $63 \cdot 9$ & 3625 & $22 \cdot 0$ & 1952 & $11 \cdot 8$ & 353 & $2 \cdot 1$ & 15 & $0 \cdot 1$ & 5945 & $36 \cdot 1$ \\
\hline
\end{tabular}

* For details of prevalence and sites, see Table 1 and Fig. 1.

$\dagger$ For details of classification, see p. 258.

would have visible goitre (data from Table 3). Prevalence did not differ between males and females in the $0-5$ years age-range $(4.1 \%$ in both), but wàs significantly higher $(P<0 \cdot 001)$ in females than in males thereafter (Table 4$)$. Of the males aged 13-18 years, 30\% were found with goitre while $45 \%$ females of the same age-group had goitre. The sex difference was even more marked in the age-group 19 years and older where the prevalence in males had decreased to $6.4 \%$ while in females it had increased to $46.0 \%$. The sex ratio of goitre was 1.0 for under 5 -year-old children $1: 1.2$ for the 6 -12-year-olds, $1: 1.5$ for the 13 -18-yearolds and 1:7.2 for the 19 years and above age-group.

As for the schoolchildren, the prevalence of goitre was higher in household members living at higher altitudes than in those at lower altitudes. The regression of gross goitre (\%) on altitude (m) (means with their standard errors) was: ( $n$ 41, $r 0.41, s 0.0083$ (SE 0.0035), $i 3.52$ (SE 6.41)).

There was a high correlation between gross goitre prevalence in schoolchildren and household members $(r 0.897, P<0.001)$. Data on gross goitre in household members were used to estimate other forms of IDD in the population of the areas surveyed. For the more severe forms in survivors, the rate of cretinism was estimated to vary from 0.09 to 16 per 1000 of the population. Assuming that the population surveyed was representative of the country, the number of cretins in Ethiopia in 1990 was estimated at $59000(1 \cdot 17$ per 1000) while three times as many, 176000 persons (3.51 per 1000), may show some degree of developmental and neurological function impairment attributable to Iodine deficiency. The estimated annual national toll in 1990 (rates per 1000 live births) of reproductive losses attributable to Iodine deficiency were as follows: neonatal deaths 13600 , stillbirths 14800 , infertility/miscarriage 20000.

From the data collected on whether excreta was disposed of in a pit latrine, water-flushed toilet or in the open air, no relationship was seen with goitre size. Neither was a relationship seen with kale consumption, seasonally or all year round, or with the source of drinking water from pipe, well, spring or river. 


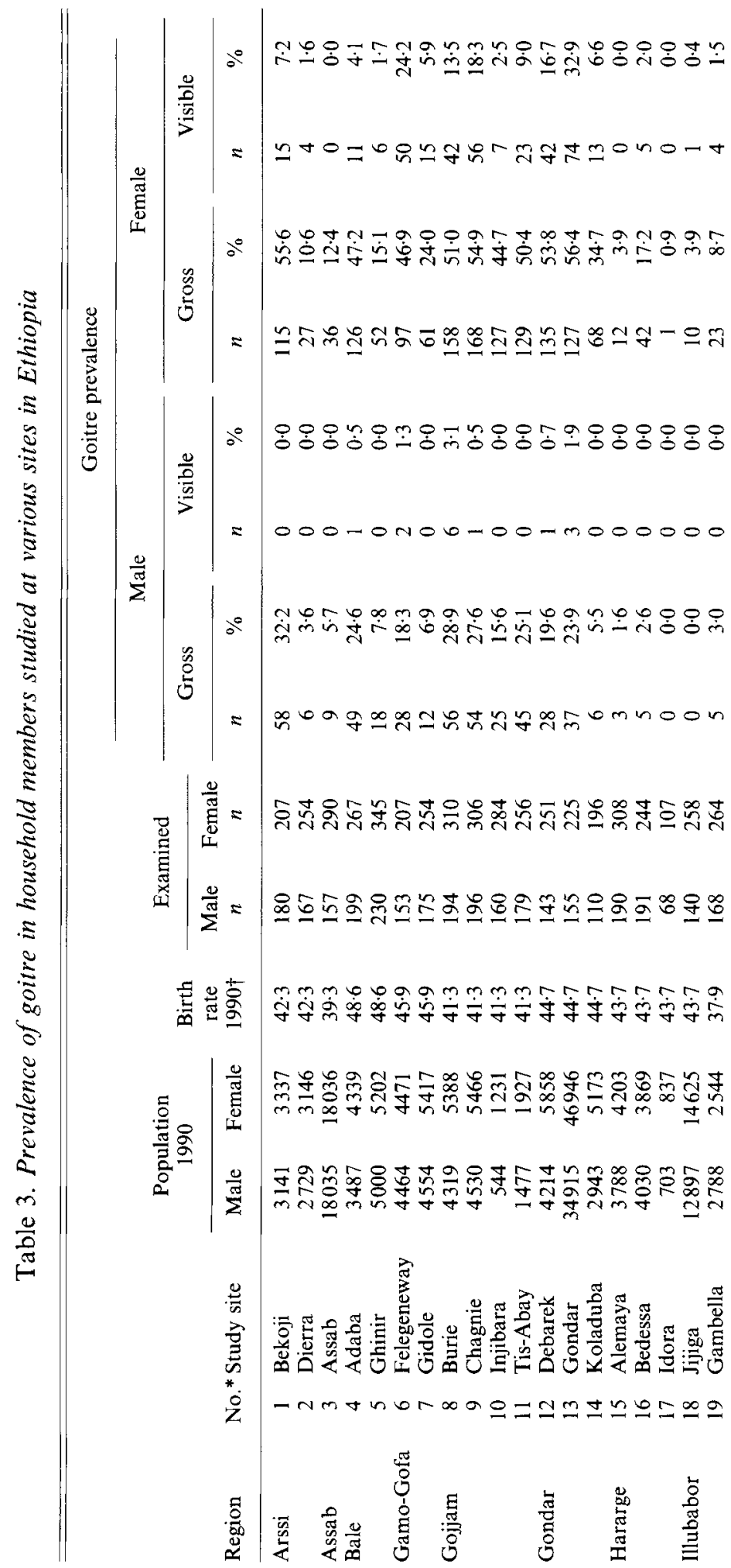




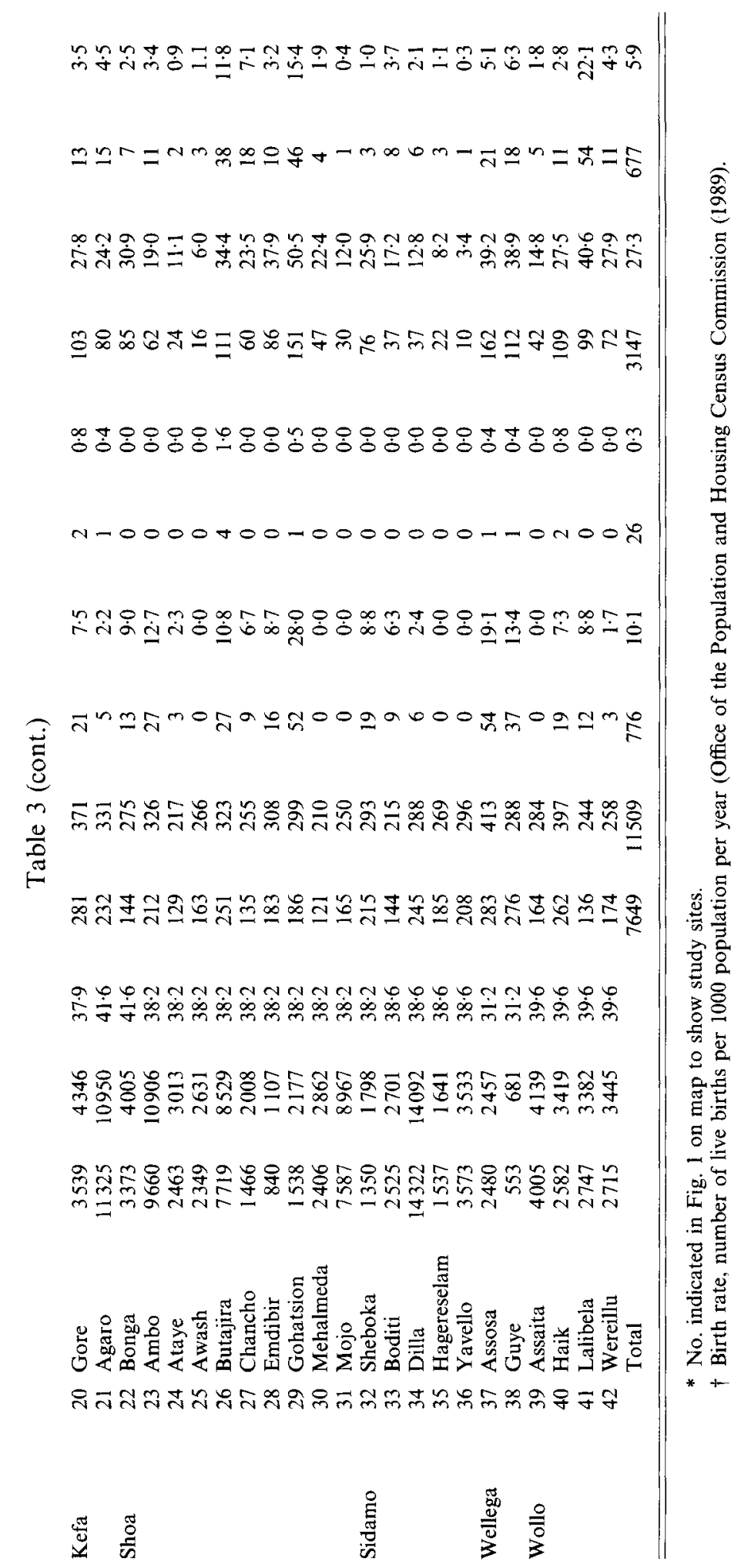


Table 4. Distribution of goitre grades by age and sex amongst all household members at various sites in Ethiopia*

\begin{tabular}{|c|c|c|c|c|c|c|c|c|c|c|c|c|c|}
\hline \multirow{3}{*}{$\begin{array}{c}\text { Age } \\
\text { (years) }\end{array}$} & \multirow{3}{*}{$\begin{array}{c}\text { No. } \\
\text { examined }\end{array}$} & \multicolumn{10}{|c|}{ Goitre grade ${ }^{\dagger}$} & & \\
\hline & & \multicolumn{2}{|c|}{0} & \multicolumn{2}{|c|}{ IA } & \multicolumn{2}{|c|}{ IB } & \multicolumn{2}{|c|}{ II } & \multicolumn{2}{|c|}{ III } & \multicolumn{2}{|c|}{ Total goitre } \\
\hline & & $n$ & $\%$ & $n$ & $\%$ & $n$ & $\%$ & $n$ & $\%$ & $n$ & $\%$ & $n$ & $\%$ \\
\hline \multicolumn{14}{|l|}{ Male } \\
\hline $0-5$ & 4079 & 3913 & $95 \cdot 9$ & 156 & $3 \cdot 8$ & 9 & 0.2 & 1 & $0 \cdot 0$ & 0 & $0 \cdot 0$ & 166 & $4 \cdot 1$ \\
\hline $6-12$ & 1951 & 1521 & $78 \cdot 0$ & 369 & 18.9 & 55 & $2 \cdot 8$ & 5 & $0 \cdot 3$ & 1 & $0 \cdot 1$ & 430 & $22 \cdot 0$ \\
\hline $13-18$ & 315 & 219 & $69 \cdot 5$ & 75 & $23 \cdot 8$ & 15 & $4 \cdot 8$ & 6 & 1.9 & 0 & $0 \cdot 0$ & 96 & $30 \cdot 5$ \\
\hline $19+$ & 1304 & 1220 & $93 \cdot 6$ & 53 & $4 \cdot 1$ & 18 & $1 \cdot 4$ & 10 & $0 \cdot 8$ & 3 & $0 \cdot 2$ & 84 & 6.4 \\
\hline Sub-total & 7649 & 6873 & 89.9 & 653 & $8 \cdot 5$ & 97 & $1 \cdot 3$ & 22 & $0 \cdot 3$ & 4 & $0 \cdot 1$ & 776 & $10 \cdot 1$ \\
\hline \multicolumn{14}{|l|}{ Female } \\
\hline $0-5$ & 4106 & 3938 & $95 \cdot 9$ & 159 & 3.9 & 4 & 0.2 & 0 & 0.0 & 0 & $0 \cdot 0$ & 168 & $4 \cdot 1$ \\
\hline $6-12$ & 2265 & 1645 & $72 \cdot 6$ & 483 & $21 \cdot 3$ & 114 & $5 \cdot 0$ & 23 & $1 \cdot 0$ & 0 & 0.0 & 620 & $27 \cdot 4$ \\
\hline $13-18$ & 652 & 356 & $54 \cdot 6$ & 152 & $23 \cdot 3$ & 90 & 13.8 & 53 & $8 \cdot 1$ & 1 & 0.2 & 296 & $45 \cdot 4$ \\
\hline $19+$ & 4486 & 2423 & $54 \cdot 0$ & 823 & $18 \cdot 3$ & 640 & $14 \cdot 3$ & 503 & $11 \cdot 2$ & 97 & $2 \cdot 2$ & 2063 & $46 \cdot 0$ \\
\hline Sub-total & 11509 & 8362 & $72 \cdot 7$ & 1617 & $14 \cdot 0$ & 853 & $7 \cdot 4$ & 579 & $5 \cdot 0$ & 98 & 0.9 & 3147 & $27 \cdot 3$ \\
\hline
\end{tabular}

* For details of prevalence and sites, see Table 1 and Fig. 1.

$\dagger$ For details of classification, see p. 258.

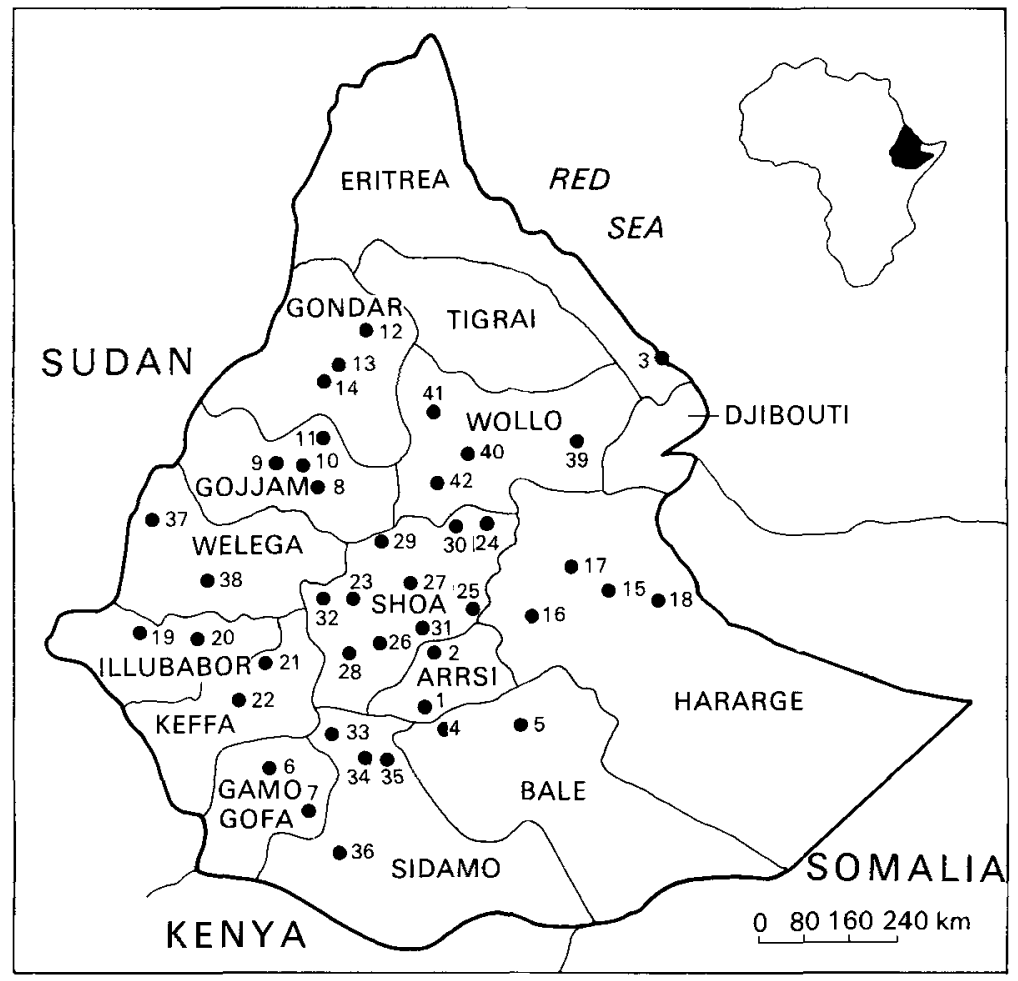

Fig. 1. Map of Ethiopia showing administrative regions and study sites. 


\section{DISCUSSION}

Studies carried out in the past have demonstrated that IDD existed in Ethiopia (Interdepartmental Committee on Nutrition for National Defence, 1959; Kelly \& Snedden, 1960; Demonstration and Evaluation Team, 1965; Popov, 1967, Hofvander, 1970; Miller et al. 1976) and that in certain pocket areas the prevalence may be as high as $71 \%$ (Miller et al. 1976). However, the present study is the first which has been designed to provide a representative overview of the severity and extent of IDD in the country. The goitre prevalence in schoolchildren found in the present survey was $30.6 \%$ which is regarded as severe according to the classification of Hetzel (1987). This rate is not as high as that reported from other African countries, such as Tanzania with 47.8\% (Kavishe, 1986). However, many surveys have not been as representative as the present survey which was stratified and covered the whole country. The present survey showed that, in schoolchildren in particular and in household members in general, the prevalence of goitre increased with age and reached its peak in the prepubertal and pubertal age in both sexes, but diminished in adulthood in males and plateaued after a slight decrease in females. These findings are in agreement with observations made elsewhere, such as in Sudan and Tanzania (Eltom et al. 1984; Kavishe, 1986). In the household study group of the present survey the sex ratio for goitre prevalence was $1: 1.5$ in subjects aged $13-18$ years and $1: 7 \cdot 2$ in those 19 years of age and over.

Studies from other areas of the world have suggested that goitre prevalence is associated with soils of Pre-Cambrian origin (Wilson, 1954; Thilly et al. 1972), suboptimal Iodine intake (Beckers \& DeLange, 1980), excessive Iodine intake possibly leading to autoimmune thyroiditis (Mu et al. 1987), high Ca, Mg and F consumption (Langer, 1960; Day \& PowellJackson, 1972; Gaitan, 1980), Se deficiency (Vanderpas et al. 1990), goitrogenic components in the diet (Ermans et al. 1980; Klopfenstein et al. 1983; Osman et al. 1983), bacterial contamination of drinking water (Gaitan, 1980) and malnutrition (Ingenbleek \& Beckers, 1973; Ingenbleek \& De Visscher, 1979; Gaitan et al. 1983). The results of the present study could find no associations with kale consumption, availability and type of latrine or source of drinking water, but a relationship was found with altitude.

There was a positive correlation between goitre prevalence and altitude amongst schoolchildren as well as household members. The correlation was relatively stronger among the household members which may be related to a longer period of exposure to a fixed Iodine intake. In addition to the relationship between goitre prevalence and altitude, there was variation in prevalence within the same range of altitude among the different study sites, particularly in lowland areas. Thus, the prevalence in household members in Felegeneway which lies at an altitude of $1430 \mathrm{~m}$ was $33 \%$ while it was less than $8 \%$ at all the other sites below $1500 \mathrm{~m}$. It is also noteworthy that next to Gondar the highest prevalence of visible goitre was observed here.

A possible explanation for goitre prevalence at high altitudes might be the leaching of Iodine from the highland areas, although no assessment of Iodine content of foods, water and soil was done during the present study. However, the Iodine content of salt from the Red Sea is low when compared with that from more open oceans (Interdepartmental Committee on Nutrition for National Defence, 1959, and a report by a World Health Organization consultant, P. Subrimanian, unpublished results). The Iodine content of food and soils from goitrous areas in Ethiopia has also been shown to be low (Z. Wolde-Gebriel and C. E. West, unpublished results). Some people in highland regions obtain their food from Iodine-rich areas and this will help to increase Iodine intake. Other factors such as goitrogens may reduce the availability of Iodine.

Assessment of schoolchildren is a simple and cheap method for determining the extent and magnitude of IDD in a community as children are readily accessible and representative. 
In the areas we surveyed, the schoolchildren were from different socio-economic groups of society and ate at home and, thus, their general dietary pattern should reflect that of the community in which they live. In the present study the prevalence rate of goitre in schoolchildren reflected that in household members. Very low or zero rates of goitre were observed both in schoolchildren and household members in certain areas such as Alemaya, Jijiga, Awash and Yavello, while high prevalence rates were observed in both groups in other areas such as Gondar, Debarek, Tis-Abay and Felegeneway.

Furthermore, the present study was conducted in semi-urban and urban areas where the inhabitants rely on food produced in the surrounding rural areas. Thus, the Iodine intake of the people surveyed may not be very different from that of those who live in the nearby surrounding areas. Since the sites sampled were evenly distributed throughout the country, we believe that the findings are representative.

Although an enlarged thyroid gland by itself does not affect a subject's health, except when the goitre is so large that it compresses the trachea, its aesthetic implications especially in girls has social implications in many rural areas. Thus, many goitrous women said that they found it difficult to find husbands and that those with large goitres did not aspire to university, after successfully passing their examination, out of fear of comments from others.

With regard to the other manifestations of IDD, excellent reviews on brain development and reproductive disorders in relation to Iodine deficiency and thyroid function have been prepared by Hetzel and his colleagues (Hetzel \& Querido, 1980; McMichael et al. 1980). Relationships between Iodine deficiency and thyroid function on the one hand, and reproductive failures, poor educational performance and physical development on the other hand have been documented from many places. These developmental IDD are very important problems of public health significance but are generally neglected by health professionals and decision makers. Applying previously-developed epidemiological models to the results from the population studied, which is assumed to be representative of the whole country, it is estimated that there are 59000 cretins and 176000 cretinoids in Ethiopia. Classically, as predicted from the epidemiological model presented, cretinism is regarded as a problem in areas where the prevalence of goitre is more than $50 \%$. From the present study we know that there are certain pocket areas with such high rates of prevalence and this could explain the existence of cretinism in such areas.

Thus, IDD would appear to be a serious threat to the health and well-being of the people residing in goitre-endemic areas. Cretins are social and economic burdens to the households and communities in which they live and to the nation as a whole. The estimates at least indicate the magnitude of the problem and highlight a very serious problem which deserves the attention of health professionals at the level of research, policy formulation and programme action, and a commitment to intervention from government. As far as research is concerned, efforts should be made to overcome the paucity of information on the impact of Iodine deficiency and Iodine supplementation on maternal welfare. As far as programmes are concerned, the salt iodination effort which has been initiated should be encouraged so that iodinated salt can reach all goitrous areas. In view of the difficult terrain and the poor transport, distribution and marketing infrastructure of the country, the use of iodized oil capsules in difficult and inaccessible areas should also be considered.

\section{REFERENCES}

Beckers, C. \& DeLange, F. (1980). Etiology of endemic goiter : iodine deficiency. In Endemic Goiter and Endemic Cretinism, pp. 199-217 [J. B. Stanbury and B. S. Hetzel, editors]. New York: Wiley.

Clugston, G. A., Dulberg, E. M., Pandav, C. S. \& Tilden, R. L. (1987). Iodine deficiency disorders in South East Asia. In The Prevention and Control of Iodine Deficiency Disorders, pp. 273-308 [B. S. Hetzel, J. T. Dunn and J. B. Stanbury, editors]. Amsterdam: Elsevier. 
Day, T. K. \& Powell-Jackson, P. R. (1972). Fluoride, water hardness, and endemic goitre. Lancet i, 1135-1138.

DeLange, F. (1974). Endemic Goitre and Thyroid Function in Central Africa. Monograph in Paediatrics. Basel: Karger.

Demonstration and Evaluation Team (1965). Ethiopian health center program, its impact on community health in three towns. Ethiopian Medical Journal 5, Suppl., 1-87.

Eltom, M., Hofvander, Y., Torelm, I. \& Fellstrom, B. (1984). Endemic goitre in the Darfur region (Sudan). Acta Medica Scandinavica 215, 467-475.

Ermans, A. M., Mbulamoko, N. M., DeLange, F. \& Ahluwalia, R. (1980). Role of Cassava in the Etiology of Endemic Goitre and Cretinism. Ottawa: International Development Research Center.

Gaitain, E. (1980). Goitrogens in the aetiology of endemic goitre. In Endemic Goitre and Endemic Cretinism, pp. 219-236 [J. B. Stanbury and B. S. Hetzel, editors]. New York: Wiley.

Gaitan, J. E., Mayoral, L. G. \& Gaitan, E. (1983). Defective thyroidal iodine concentration in protein-calorie malnutrition. Journal of Clinical Endocrinology and Metabolism 57, 327-333.

Hetzel, B. S. (1987). An overview of the prevention and control of iodine deficiency disorders. In The Prevention and Control of Iodine Deficiency Disorders, pp. 7-31 [B. S. Hetzel, J. T. Dunn and J. B. Stanbury, editors]. Amsterdam: Elsevier.

Hetzel, B. S., Potter, B. J. \& Dulberg, E. M. (1990). The iodine deficiency disorders: nature, pathogenesis and epidemiology. World Review of Nutrition and Dietetics 62, 59-119.

Hetzel, B. S. \& Querido, A. (1980). Iodine deficiency, thyroid function, and brain development. In Endemic Goitre and Endemic Cretinism, pp. 461-472 [J. B. Stanbury and B. S. Hetzel, editors]. New York: Wiley.

Hofvander, Y. (1970). Endemic goitre among children in the Ethiopian highlands. Ethiopian Medical Journal 8 , $179-184$.

Ingenbleek, Y. \& Beckers, C. (1973). Evidence for intestinal maladaptation of iodine in protein energy malnutrition. American Journal of Clinical Nutrition 26, 1323-1330.

Ingenbleek, Y. \& De Visscher, M. (1979). Hormonal and nutritional status: critical conditions for endemic goitre epidemiology? Metabolism 28, 9-19.

Interdepartmental Committee on Nutrition for National Defence (1959). Ethiopia-Nutrition Survey. Washington, DC: US Government Printing Office.

Kavishe, F. P. (1986). The prevalence and control of endemic goitre in Tanzania. In Towards the Eradication of Endemic Goitre, Cretinism and Iodine Deficiency. Scientific Publication no. 502, pp. 332-334 [J. T. Dunn, E. A. Pretell, C. H. Daza and F. E. Viteri, editors]. Washington, DC: PAHO/WHO.

Kelly, F. C. \& Snedden, W. W. (1960). Prevalence and geographical distribution of endemic goitre. In Endemic Goitre. WHO Monograph Series no. 44, pp. 27-333. Geneva: WHO.

Kloos, H., Adugna, A. \& Sahlu, E. (1988). The physical biotic and human environment in Ethiopia: The perspective of medical geography. In The Ecology of Health and Disease in Ethiopia, pp. 18-42 [Z. A. Zein and H. Kloos, editors]. Addis Ababa: Ministry of Health.

Klopfenstein, C. F., Hoseney, R. C. \& Leipold, H. W. (1983). Goitrogenic effects of pearl millet diets. Nutrition Reports International 27, 1039-1047.

Langer, P. (1960). History of goitre. In Endemic Goitre. WHO Monograph Series no. 44, pp. 9-25. Geneva: WHO.

McMichael, A. J., Potter, J. D. \& Hetzel, B. S. (1980). Iodine deficiency, thyroid function, and reproductive failure. In Endemic Goitre and Endemic Cretinism, pp. 445-460 [J. B. Stanbury and B. S. Hetzel, editors]. New York: Wiley.

Miller, D. S., Baker, J., Bowden, M., Evans, E., Holt, J., McKeag, R. J., Meinertzhagen, I., Mumford, P. M., Oddy, D. J., Rivers, J. P. W. R., Sevenhuysen, G., Stock, M. J., Kebebe, A., Wolde-Gebriel, Y. \& WoldeGebriel, Z. (1976). The Ethiopia applied nutrition project. Proceedings of the Royal Society, London 194, 2348.

Mu, L., Derun, L., Chengyi, Q., Peiying, Z., Qidong, Q., Chunde, Z., Qingzhen, J., Huaixing, W., Eastman, C. J., Boyages, S. C., Collins, J. K., Jupp, J. J. \& Maberly, G. F. (1987). Endemic goitre in central China caused by excessive iodine intake. Lancet ii, 257-258.

Office of the Population and Housing Census Commission (1984). Population and Housing Census. Addis Ababa: OPHCC.

Office of the Population and Housing Census Commission (1989). Population and Housing Census, Analytical Reports on the Various Administrative Regions. Addis Ababa: OPHCC.

Osman, K. A., Basu, T. K. \& Dickerson, J. (1983). A goitrogenic agent from millet (Pennisetum typhoides) in Darfur province, Western Sudan. Annals of Nutrition and Metabolism 27, 1418.

Perez, C., Scrimshaw, N. S. \& Mũnoz, J. A. (1960). Technique of endemic goitre surveys. In Endemic Goitre. WHO Monograph Series no. 44. pp. 369-383. Geneva: WHO.

Popov, L. (1967). Medical study of goitre in Ethiopia. Ethiopian Medical Journal 6, 5-14.

Thilly, C. H., DeLange, F. \& Ermans, A. M. (1972). Further investigations of iodine deficiency in aetiology of endemic goitre. American Journal of Clinical Nutrition 25, 30-40.

Vanderpas, J. B., Contempré, B., Duale, N. L., Goosseens, W., Bebe, N., Thorpe, R., Ntambue, K., Dumont, J., Thilly, C. H. \& Diplock, A. T. (1990). Iodine and selenium deficiency associated with cretinism in northern Zaire. American Journal of Clinical Nutrition 52, 1087-1093.

Wilson, D. C. (1954). Goitre in Ceylon and Nigeria. British Journal of Nutrition 8, 90-99. 